\title{
Indium-Catalyzed Cycloisomerization into Medium-Sized Rings
}

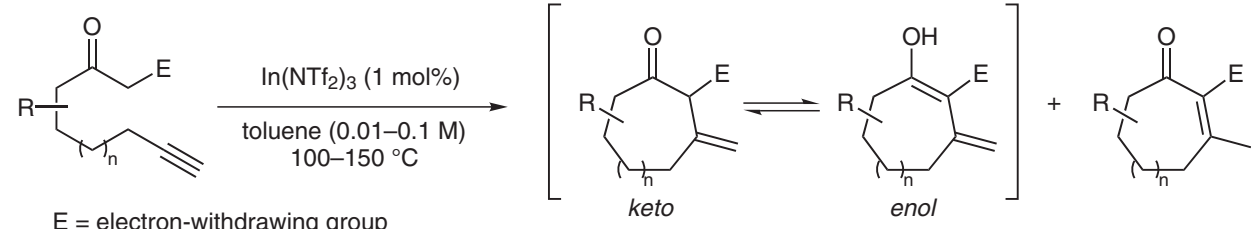

Examples:

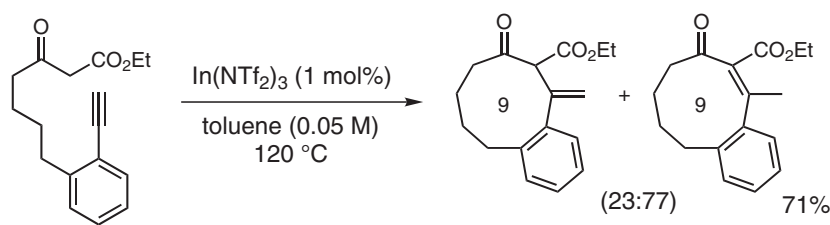<smiles>C#CCCc1ccccc1-c1ccccc1CC(=O)CC(C)=O</smiles><smiles>C#CCCCCC(=O)CC(C)=O</smiles>
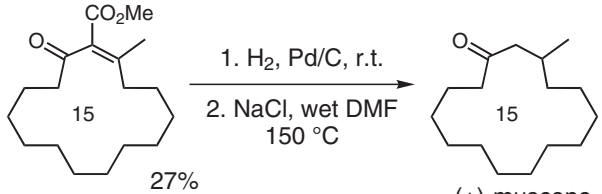

( \pm -muscone

Significance: The intramolecular Conia reaction was extended to the preparation of medium-sized and large (6- to 15-membered) rings. The reaction proceeds under moderately dilute conditions and the medium-sized rings are obtained even more readily than six-membered rings. This anomalous relationship between the ring size and the cyclization rate makes this reaction a powerful tool for the preparation of medium-sized to large rings, which are important scaffolds for natural products and odorants.
Comment: In(NTf $)_{3}$ was identified as the optimal catalyst for the cycloisomerization reaction of $\omega$-alkynyl- $\beta$-keto esters. Only low amounts of the catalyst (1 mol\%) are necessary due to a dual activation of both enolate and acetylenic moieties. 8- to 10-Membered rings, which are difficult to access by conventional methods because of unfavorable entropic effects and transannular interactions, were formed in good yields. The reaction also provided an easy access to muscone which could be prepared in two steps starting from the corresponding $\omega$-alkynyl- $\beta$-keto ester. 